\title{
Milhos com diferentes texturas de endosperma e adição de alfa-amilase na dieta de leitões
}

\author{
The effect of corn kernel texture and alpha-amylase addition in performance and digestibility of diets \\ for weaned pigs
}

\author{
Vanessa Piovesan ${ }^{\mathrm{I}}$ Vladimir de Oliveira ${ }^{\mathrm{II}}$ Clóvis Eliseu Gewehr ${ }^{\mathrm{III}}$
}

\section{RESUMO}

Dois experimentos foram realizados para avaliar a influência de milhos com diferentes texturas de endosperma $e$ adição de alfa amilase na digestibilidade de dietas e no desempenho de leitões na fase de creche. No ensaio de digestibilidade, foram usados 12 leitões castrados $(7,96 \pm 0,31 \mathrm{~kg})$, alojados individualmente em gaiolas de metabolismo, enquanto no desempenho utilizaram-se 75 leitões $(7,87 \pm 0,67 \mathrm{~kg})$ distribuídos em 15 gaiolas de creche. Nos dois experimentos, os tratamentos consistiram de três dietas formuladas para serem isonutritivas, mas com milhos de diferentes texturas e adição ou não de alfa amilase, conforme descrito a seguir: 1. grãos de milho semi-dentado; 2. grãos de milho duro e; 3. grãos de milho duro + alfa-amilase. Os resultados de metabolismo mostraram que os valores de energia digestível (ED) e metabolizável (EM) das dietas foram influenciados pelos tipos de milho, sendo o semi-dentado superior $(P<0,05)$ ao milho duro (3872 versus $3767 \mathrm{kcal}$ ED

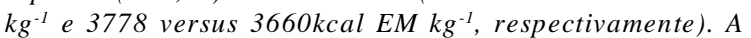
inclusão de amilase à dieta com milho duro fez com que os valores de ED e EM $(P<0,05)$ se aproximassem dos valores obtidos com milho semi-dentado (3872 versus $3826 \mathrm{kcal}$ ED

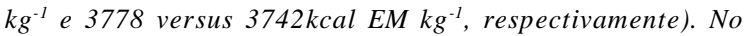
experimento de desempenho, não foram observadas diferenças $(P>0,05)$ entre os tratamentos no consumo de ração, ganho de peso elou conversão alimentar. Dietas com milho duro ou semi-dentado e adição de alfa-amilase não alteram o desempenho dos leitões. Por outro lado, dietas contendo milho semi-dentado apresentam maior energia digestível que dietas com milho duro e a adição de alfa-amilase aumenta a energia de dietas com milho duro.

Palavras-chave: amido, digestibilidade, nutrição animal, suinocultura.

\begin{abstract}
Two experiments were carried out to evaluate the effects of diets with different corn grain textures and amylase supplementation on nutrients digestibility and nursery piglets' performance. Twelve castrated piglets $(7.96 \pm 0.31 \mathrm{~kg})$ were individually housed in metabolic crates and 75 piglets $(7.87 \pm 0.67 \mathrm{~kg})$ penned in 15 nursery pens. In both experiments the treatments consisted of three isonutritive diets: 1. semi dent corn grain; 2. flint corn grain, and 3. flint corn grain + amylase. There was effect of treatments $(P<0.05)$ in digestible $(D E)$ and metabolisable energy $(M E)$, with the semi dent corn grain diet having DE and ME higher values (3872 versus $3767 \mathrm{kcal} D E$

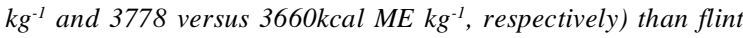
dent corn grain diet. The amylase addition increased the $D E$

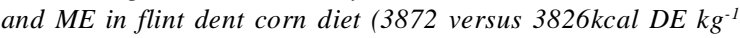

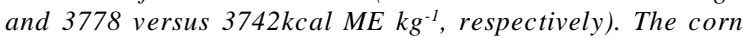
grain characteristics didn't influence $(P<0.05)$ feed intake, average daily gain and feed conversion and amylase addition didn't affect $(P>0.05)$ the performance characteristics studied. In conclusion, diets with flint or semi dent corns and amylase supplementation did not improve the performance of piglets. On the other hand, semi dent corn diet has more digestible energy in comparison with flint corn diet and amylase addition increase energy values of flint corn diet.
\end{abstract}

Key words: animal nutrition, digestibility, starch, swine production.

\section{INTRODUÇÃO}

O milho é incorporado nas dietas de suínos em proporções que variam entre 50 a $80 \%$ e tem como

'Programa de Pós-graduação em Zootecnia, Universidade Estadual do Oeste do Paraná (UNIOESTE), Marechal Cândido Rondon, PR, Brasil.

"Departamento de Zootecnia e Desenvolvimento Rural, Centro de Ciências Agrárias (CCA), Universidade Federal de Santa Catarina (UFSC), Florianópolis, SC, Brasil. E-mail:vladimir@cca.ufsc.br. Autor para correspondência.

IIIDepartamento de Produção Animal e Alimentos, Centro de Ciências Agroveterinárias, Universidade do Estado de Santa Catarina (UDESC), Lages, SC, Brasil. 
principal função fornecer energia para os diferentes processos metabólicos. Grande parte da energia que os suínos conseguem extrair do milho é oriunda da oxidação de moléculas de glicose que formam o amido.

Nos grãos de cereais, o amido constitui a maior parte do endosperma, sendo armazenado em estruturas denominadas grânulos. No caso do milho, o endosperma é dividido em farináceo e vítreo, cada qual com características físico-químicas específicas (HOSENEY, 1994). Os grãos de milho duro possuem maior proporção de endosperma vítreo, enquanto milhos dentados ou moles possuem maior proporção de endosperma farináceo. No Brasil, as opções de cultivares disponibilizadas na safra de 2010/2011 foram de 26,03; 54,01, e 5,00 para os milhos duro, semi-duroe dentado, respectivamente (CRUZ et al., 2010). Os milhos duro e semi-duro são preferidos, pois são menos suceptíveis ao ataque de pragas e perdas durante o processamento.

Os grânulos de amido do endosperma farináceo podem ser mais susceptíveis à ação enzimática, porque a matriz protéica que os circundam é relativamente fina e incompleta, apresentando espaços vazios e menor densidade (HUNTINGTON, 1997). Ao contrário, os grânulos de amido do endosperma vítreo são embebidos por uma matriz protéica espessa e contínua, tornando-os menos acessíveis às enzimas amilolíticas (CHOCT et al., 2001). Além disso, os grânulos de amido do endosperma vítreo formam uma estrutura compacta e mais densa, quando comparada ao endosperma farináceo (HUNTINGTON, 1997).

A dureza é uma característica física que influencia na qualidade e no processamento dos grãos de milhos e a vitreosidade é uma medida indireta da dureza do grão (FOX \& MANLEY, 2009). A proporção de endosperma vítreo em relação ao endosperma total, obtida por dissecação dos grãos, também é denominada de vitreosidade (PHILIPPEAU \& DOREAU, 1998; CORREA et al., 2002). Resultados de experimentos realizados com suínos em crescimento demonstram a existência de associação negativa entre dureza e digestão do milho(CANTARELLI et al., 2007).

A influência negativa da dureza do grão sobre o desempenho animal pode ser mais pronunciada em leitões na fase de creche, pois, nas primeiras semanas pós-desmame, a capacidade de digestão dos alimentos fica comprometida. Isso é particularmente verdadeiro para a digestão de carboidratos de origem vegetal, uma vez que, durante a lactação, a principal fonte de carboidrato disponível aos leitões é a lactose (WISEMAN et al., 2000). Sabe-se que ocorre aumento na atividade da amilase pancreática após o desmame, provavelmente devido à necessidade de digestão do amido da ração (LINDEMANN et al., 1986). Contudo, muitos fatores influenciam na quantidade de enzimas secretadas, reduzindo a digestão intestinal do amido pelos leitões. Vários autores apontam os efeitos positivos da suplementação de enzimas exógenas sobre a digestão dos alimentos (CLASSEN, 1996; COWIESON, 2005).

Baseado nessas informações, é possível supor que a adição de amilase na ração de leitões na fase de creche aumente a digestão do amido e, em decorrência, a digestibilidade da energia de milhos com alta vitreosidade, que são os mais cultivados no Brasil. Diante disso, dois experimentos foram realizados com os objetivos de verificar o efeito da textura do endosperma do milho e a adição de amilase na digestibilidade dos nutrientes das dietas e no desempenho de leitões na fase de creche.

\section{MATERIAL E MÉTODOS}

Foram utilizadas duas variedades de milho disponíveis comercialmente e selecionadas para o estudo em razão de suas características de endosperma. O cultivo foi conduzido em solos com características químicas e físicas idênticas e todas as práticas culturais foram iguais para as duas variedades.

Os tratamentos experimentais avaliados no ensaio de metabolismo e desempenho consistiram de três dietas formuladas a base de milho, farelo de soja, minerais e vitaminas (Tabela 1), tendo como únicas diferenças os tipos de milho e a adição de enzima, segundo o esquema a seguir: 1. Ração com milho semidentado; 2. Ração com milho duro; e, 3. Ração com milho duro e adição de alfa-amilase na proporção de $0,06 \%$. Foi utilizada uma enzima alfa-amilase comercial de origem fúngica, com atividade enzimática mínima de 4.000SKB $\mathrm{g}^{-1}$, e nível de inclusão conforme recomendado pelo fabricante. O SKB (SandstedtKneen-Blish) descreve a quantidade de gramas de amido hidrolizada por um grama de amilase em condições ótimas de $\mathrm{pH}$ e temperatura durante o período de uma hora. As dietas foram formuladas para atender ou superar os níveis nutricionais recomendados pelo National Research Council (NRC, 1998), conforme apresentado na tabela 2 .

No ensaio de metabolismo, foram utilizados 12 suínos castrados com peso médio inicial de $7,96 \pm 0,31 \mathrm{~kg}$ distribuídos em um delineamento de blocos casualizados. Os animais foram alojados individualmente em gaiolas de metabolismo projetadas para leitões na fase de creche durante 12 dias, sendo sete para adaptação e cinco para coleta total de fezes e urina. A ração foi umedecida (2:1; ração: água) e fornecida duas vezes ao dia (08h e $16 \mathrm{~h})$. Os demais procedimentos experimentais foram realizados de acordo com o descrito por OLIVEIRA et al. (2001).

As variáveis analisadas foram coeficiente de digestibilidade da matéria seca (CDMS), matéria orgânica (CDMO), proteína bruta (CDPB), amido (CDAMID), coeficiente energia bruta (CDEB), coeficiente de metabolizabilidade da energia bruta (CMEB), energia digestível (ED) e energia metabolizável (EM).

No experimento de desempenho, foram utilizados 75 leitões com peso médio inicial de 
Tabela 1 - Composição química de dietas experimentais contendo diferentes texturas de milho e adição de amilase, expressos na matéria natural.

\begin{tabular}{|c|c|c|c|}
\hline Composição & Semi-dentado & Duro & Duro + amilase \\
\hline Energia metabolizável $^{1}\left(\mathrm{kcal} \mathrm{kg}^{-1}\right)$ & 3300 & 3300 & 3300 \\
\hline Proteína bruta $^{2}(\%)$ & 19,92 & 19,36 & 19,36 \\
\hline $\left.\operatorname{Amido}^{2}\right)(\%)$ & 36,83 & 36,96 & 36,96 \\
\hline Cálcio $^{1}(\%$ & 0,75 & 0,75 & 0,75 \\
\hline Fósforo disponível ${ }^{1}(\%)$ & 0,35 & 0,35 & 0,35 \\
\hline 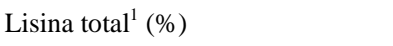 & 1,30 & 1,30 & 1,30 \\
\hline 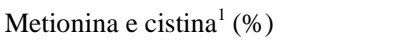 & 0,69 & 0,69 & 0,69 \\
\hline Treonina $^{1}(\%)$ & 0,90 & 0,90 & 0,90 \\
\hline Energia metabolizável ${ }^{1}\left(\mathrm{kcal} \mathrm{kg}^{-1}\right)$ & 3300 & 3300 & 3300 \\
\hline Proteína bruta ${ }^{2}(\%)$ & 20,10 & 19,39 & 19,39 \\
\hline $\operatorname{Amido}^{2}(\%)$ & 46,49 & 46,65 & 46,65 \\
\hline Cálcio $^{1}(\%)$ & 0,70 & 0,70 & 0,70 \\
\hline Fósforo disponível ${ }^{1}(\%)$ & 0,35 & 0,35 & 0,35 \\
\hline Lisina $\operatorname{total}^{1}(\%)$ & 1,20 & 1,20 & 1,20 \\
\hline Metionina e cistina $^{1}(\%)$ & 0,65 & 0,65 & 0,65 \\
\hline Treonina $^{1}(\%)$ & 0,85 & 0,85 & 0,85 \\
\hline
\end{tabular}

${ }^{1}$ Calculado segundo ROSTAGNO et al. (2005).

${ }^{2}$ Laboratorio de Nutrição Animal - Unioeste.

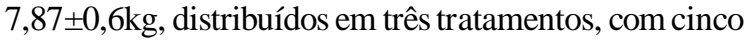
repetições, usando o delineamento em blocos casualizados, com base no peso inicial. Os animais foram

Tabela 2 - Ingredientes de dietas experimentais contendo milho com diferentes texturas e adição de amilase.

\begin{tabular}{|c|c|c|c|}
\hline \multirow[b]{2}{*}{ Ingredientes $(\mathrm{kg})$} & \multicolumn{3}{|c|}{----------------Dieta---------------- } \\
\hline & $\begin{array}{l}\text { Semi- } \\
\text { dentado }\end{array}$ & Duro & $\begin{array}{l}\text { Duro + } \\
\text { amilase }\end{array}$ \\
\hline \multicolumn{4}{|c|}{ 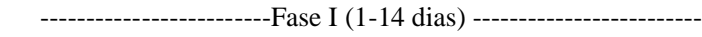 } \\
\hline Milho semi-dentado & 50,00 & - & - \\
\hline Milho duro & - & 50,00 & 50,00 \\
\hline Farelo de soja & 25,00 & 25,00 & 25,00 \\
\hline Núcleo $^{1}$ & 25,00 & 25,00 & 25,00 \\
\hline Alfa-amilase ${ }^{2^{*}}$ & - & - & 0,06 \\
\hline Milho semi-dentado & 63,00 & - & - \\
\hline Milho duro & - & 63,00 & 63,00 \\
\hline Farelo de soja & 32,00 & 32,00 & 32,00 \\
\hline Núcleo $^{1}$ & 5,00 & 5,00 & 5,00 \\
\hline Alfa-amilase ${ }^{2^{*}}$ & - & - & 0,06 \\
\hline
\end{tabular}

${ }^{1}$ Contendo lactose, soro de leite em pó, açúcar, óleo vegetal, farinha de peixe, antioxidante, minerais e vitaminas.

${ }^{2}$ Enzima alfa-amilase $4.000 \mathrm{SKB}$. *incluída em substituição ao milho. distribuídos em 15 gaiolas creche contendo três machos castrados e duas fêmeas.

Foram analisados o consumo diário de ração em gramas (g), o ganho de peso diário $(\mathrm{g})$ e a conversão alimentar $\left(\mathrm{g} \mathrm{g}^{-1}\right)$. Para a avaliação do ganho de peso, os animais foram pesados individualmente no início, aos 14 e aos 28 dias de alojamento. A conversão alimentar foi obtida pela relação entre o consumo de ração e $o$ ganho de peso durante o período experimental. A matéria seca, proteína bruta, matéria mineral e energia bruta digestível e metabolizável foram realizadas conforme metodologias descritas por SILVA \& QUEIROZ (2002). O amido foi determinado de acordo com o processo descrito no Compêndio Brasileiro de Alimentação Animal (1992). Os dados obtidos foram submetidos à análise de variância e as comparações entre as diferentes médias foram feitas pelo teste de Tukey a $5 \%$ de probabilidade.

\section{RESULTADOS E DISCUSSÃO}

As diferentes médias entre os tratamentos nos coeficientes de digestibilidade (CD), da matéria seca (CDMS), matéria orgânica (CDMO), proteína bruta (CDPB), amido (CDAMID) e da energia bruta (CDEB), digestível (CDED) e metabolizabilidade da energia bruta (CDMEB) não foram suficientes para serem detectadas pela análise estatística (Tabela 3). Por outro lado, os 
Tabela 3 - Coeficientes de digestibilidade da matéria seca (CDMS), matéria orgânica (CDMO), proteína bruta (CDPB), amido (CDAMID), energia bruta (CDEB), energia digestível (ED), metabolizabilidade da energia bruta (CDMEB) e energia metabolizável (EM) das dietas com milhos de diferentes texturas e com adição de amilase para leitões na dase de creche, expressos na matéria seca.

\begin{tabular}{|c|c|c|c|c|c|}
\hline \multirow{2}{*}{ Item } & \multicolumn{3}{|c|}{ - } & \multirow{2}{*}{ EPM } & \multirow{2}{*}{ Efeito Tratamento } \\
\hline & Semi-dentado & Duro & Duro + Amilase & & \\
\hline CDMS $(\%)$ & 86,99 & 86,55 & 86,80 & 0,71 & NS \\
\hline CDMO $(\%)$ & 88,66 & 88,10 & 88,38 & 0,73 & NS \\
\hline CDPB $(\%)$ & 85,98 & 84,73 & 83,91 & 1,41 & NS \\
\hline CDAMID (\%) & 94,52 & 95,01 & 95,43 & 0,56 & NS \\
\hline $\mathrm{CDEB}(\%)$ & 87,29 & 86,42 & 86,93 & 0,78 & NS \\
\hline $\mathrm{ED}\left(\mathrm{kcal} \mathrm{kg}^{-1}\right)$ & $3872^{\mathrm{a}}$ & $3767^{\mathrm{b}}$ & $3826^{\mathrm{ab}}$ & 29,74 & $<0,05$ \\
\hline CDMEB (\%) & 85,17 & 83,96 & 85,02 & 0,74 & NS \\
\hline $\mathrm{EM}\left(\mathrm{kcal} \mathrm{kg}^{-1}\right)$ & $3778^{a}$ & $3660^{\mathrm{b}}$ & $3742^{\mathrm{ab}}$ & 29,84 & $<0,05$ \\
\hline
\end{tabular}

$\mathrm{EPM}=$ erro padrão da média amostral.

${ }^{\mathrm{NS}}$ Não-significativo pelo teste $\mathrm{F}(\mathrm{P}>0,05)$.

Médias seguidas de letras diferentes na mesma linha diferem pelo teste de Tukey $(\mathrm{P}<0,05)$.

valores de energia digestível (ED) e metabolizável (EM) foram influenciados pelos tratamentos $(\mathrm{P}<0,05)$, sendo que as dietas contendo milho semi-dentado apresentaram ED e EM superior às constituídas por milho duro $(\mathrm{P}<0,05)$.

Supõe-se que os valores superiores de ED e EM das dietas contendo milho semi-dentado ocorreram em razão das características de seu endosperma, que possui menor proporção de endosperma vítreo, quando comparado com o milho duro. No endosperma vítreo, os grânulos de amido são compactados em uma matriz protéica densa e espessa (TESTER \& QI, 2004), o que dificulta o acesso de enzimas e a digestão do amido (KOTARSKI et al., 1992; CHOCT et al., 2001; DENARDIN \& SILVA, 2009).

Apesar dos maiores valores de ED e EM do milho semi-dentado, os coeficientes de digestibilidade do amido das dietas não foram influenciados $(\mathrm{P}>0,05)$ pelo tipo de milho, contrariando a hipótese anterior. Entretanto, é preciso considerar que a digestibilidade total pode superestimar a digestibilidade ileal, pois o amido que atinge o intestino grosso é rapidamente utilizado pelos microrganismos para produção de energia ou ácidos graxos voláteis. Assim, valores de digestibilidade total podem não refletir diferenças na taxa de digestão do amido no intestino delgado. WEURDING et al. (2001) constataram que amidos de diferentes fontes possuem digestibilidade fecal semelhante, mas digestibilidade ileal diferente.

Em estudo realizado com leitões dos 8 aos $15 \mathrm{~kg}$, não foi verificada diferença na ED do milho dentado e duro, apesar de o milho dentado apresentar valor de ED 70 $\mathrm{kcal} \mathrm{kg}^{-1}$ superior ao milho duro (NETO, 2006). Em outro trabalho, CANTARELLI et al. (2007), trabalhando com suínos em crescimento, não verificaram diferenças na ED entre milhos semi-dentado e duro, apesar de o milho semi-dentado ter $100 \mathrm{kcal} \mathrm{kg}^{-1} \mathrm{a}$ mais de ED que o milho duro.

A inclusão de amilase nas dietas com milho duro proporcionou aumento $(\mathrm{P}<0,05)$ dos valores de energia digestível e metabolizável, fazendo com que a ED e EM se aproximassem $(\mathrm{P}>0,05)$ da energia obtida com dietas constituídas de milho semi-dentado (3826 versus 3872 e 3742 versus $3778 \mathrm{kcal} \mathrm{kg}^{-1}$ de ED e EM, respectivamente).

Nas primeiras semanas após o desmame, os leitões podem apresentar secreção insuficiente de enzimas, o que compromete a digestão dos alimentos e provoca problemas digestivos. A amilase é uma das enzimas que tem pouca atividade imediatamente após o desmame (LINDEMANN et al., 1986; JENSEN et al., 1997) e a amilase exógena pode ter contribuído para o aumento da taxa de digestão do amido contido no endosperma vítreo.

Em outro estudo, não foi encontrado efeito de amilase bacteriana na ED e EM de dietas para leitões com peso inicial aproximado de $17,5 \mathrm{~kg}$ (NERY et al., 2000). O peso vivo inicial dos animais utilizados no ensaio de metabolismo no presente experimento (7,96kg) foi inferior ao de NERY et al. (2000) e isso pode ter determinado as diferenças observadas entre os dois experimentos. Acredita-se que a dificuldade para digerir o amido seja transitória, ocorrendo apenas nas primeiras semanas após o desmame (LINDEMANN et al., 1986; WISEMAN et al., 2000).

Os tratamentos experimentais não influenciaram nas variáveis de desempenho estudadas (Tabela 4). Os maiores valores de energia das dietas 
Tabela 4 - Peso inicial (PI), peso final (PF), consumo de ração diário (CRD), ganho de peso diário (GPD) e conversão alimentar (CA) de leitões consumindo dietas com milhos de diferentes texturas e com adição de amilase na fase de creche.

\begin{tabular}{|c|c|c|c|c|c|}
\hline \multirow{2}{*}{ Item } & \multirow[b]{2}{*}{ Semi-dentado } & \multirow[b]{2}{*}{ Duro } & \multirow[b]{2}{*}{ Duro+amilase } & \multirow{2}{*}{ EPM } & \multirow{2}{*}{ Efeito Tratamento } \\
\hline & & & & & \\
\hline $\mathrm{PI}(\mathrm{g})$ & 7.776 & 7.619 & 7.772 & - & - \\
\hline $\mathrm{PF}(\mathrm{g})$ & 23.519 & 22.939 & 23.091 & & \\
\hline CRD (g) & 802 & 800 & 798 & 0,07 & NS \\
\hline GPD (g) & 562 & 554 & 547 & 0,13 & NS \\
\hline $\mathrm{CA}\left(\mathrm{g} \mathrm{g}^{-1}\right)$ & 1,43 & 1,45 & 1,46 & 0,33 & NS \\
\hline
\end{tabular}

$\mathrm{EPM}=$ erro padrão da média amostral.

${ }^{\mathrm{NS}}$ Não-significativo pelo teste de $\mathrm{F}(\mathrm{P}>0,05)$.

Médias seguidas de mesma letra na mesma linha não diferem pelo teste de Tukey $(\mathrm{P}>0,05)$.

com milho semi-dentado e milho duro com adição de amilase observados no ensaio de metabolismo não provocaram alterações no desempenho dos leitões. Esses resultados podem ter ocorrido devido ao conteúdo de energia das dietas experimentais ter sido suficiente para atender as exigências nutricionais. A dieta com milho duro, que apresentou o menor valor de energia, teve $3290 \mathrm{kcal} \mathrm{ED} \mathrm{kg}^{-1}$ (ajustado para 88\% de matéria seca), valor próximo aos recomendados para dietas de leitões (NRC, 1998; ROSTAGNO et al., 2005).

\section{CONCLUSÃO}

Dietas formuladas para leitões na fase de creche com milho semi-dentado apresentam maior energia digestível e metabolizável que dietas formuladas com milho duro e a adição de amilase aumenta a energia digestível e metabolizável das dietas contendo milho duro.

Dietas contendo milhos de textura semidentada e dura e a adição de alfa-amilase em dietas contendo milho de textura dura não altera o desempenho dos leitões.

\section{REFERÊNCIAS}

CANTARELLI, V. S. et al. Composição química, vitreosidade e digestibilidade de diferentes híbridos de milho para suínos. Ciência e Agrotecnologia, v.31, p.860-864, 2007. Disponível em: <http://www.scielo.br/pdf/cagro/v31n3/ a36v31n3.pdf>. Acesso em: 15 dez. 2009. doi: 10.1590/S141370542007000300036 .

CHOCT, M. et al. Microstructure of grains as an indicator of nutritive value. Recent Advances in Animal Nutrition in Australia, v.13, p.223-228, 2001. Disponível em: <http://ses.library.usyd.edu.au/ bitstream/2123/2620/1/ Choct_M._etal_2001b.pdf>. Acesso em: 15 dez. 2009.
CLASSEN, H.L. Cereal grain starch and exogenous enzymes in poultry diets. Animal Feed Science and Technology, v.62, p.21-27, 1996.

COMPÊNDIO BRASILEIRO DE ALIMENTAÇÃO ANIMAL. Ministério da Agricultura e Abastecimento. Matéria-prima. Brasília: Sindirações/ANFAR:CBNA, SDR/MA, 1992. p.99102. (Método n.34).

CORREA, C.E.S. et al. Relationship between corn vitreousness and ruminal in situ starch degradability. Journal of Dairy Science, v.85, p.3008-3012, 2002. Disponível em: <http:// jds.fass.org/cgi/reprint/85/11/3008.pdf $>$. Acesso em: $15 \mathrm{dez}$. 2009.

COWIESON, A.J. Factors that affect the nutritional value of maize for broilers. Animal Feed Science and Technology, v.119, p.293-305, 2005.

CRUZ, J.C. et al. [2010]. Milho - cultivares para 2010/ 2011. Disponível em: < http://www.cnpms.embrapa.br/milho/ cultivares/index.php>. Acesso em: 15 jun. 2011.

DENARDIN, C.C.; SILVA, L.P. Estrutura dos grânulos de amido e sua relação com propriedades físico-químicas. Ciência Rural, v.39, p.945-954, 2009. Disponível em: <http://www.scielo.br/ pdf/cr/v39n3/a109cr517.pdf $>$. Acesso em: 15 dez. 2009. doi: 10.1590/S0103-84782009005000003.

FOX, G.; MANLEY, M. Hardness methods for testing maize kernels. Journal Agriculture Food Chemistry, v.57, p.5647-5657, 2009. Disponível em: <http://pubs.acs.org/doi/ abs/10.1021/jf900623w>. Acesso em: 15 dez. 2009. doi: $10.1021 /$ jf900623w.

HOSENEY, R.C. Principles of cereal science and technology. 2.ed. St Paul: American Association of Cereal Chemists, 1994. 378p.

HUNTINGTON, G.B. Starch utilization by ruminants: from basics to bulk. Journal of Animal Science, v.75, p.852-867, 1997. Disponível em: <http://jas.fass.org/cgi/reprint/75/3/ 852.pdf>. Acesso em: 15 dez. 2009.

JENSEN, M.S. et al. Development of digestive enzymes in pigs with emphasis on lipolytic activity in the stomach and pancreas.

Ciência Rural, v.41, n.11, nov, 2011. 
Journal of Animal Science, v.75, p.437-445, 1997. Disponível em: < http://jas.fass.org/cgi/reprint/75/2/437.pdf >. Acesso em: 15 dez. 2009.

KOTARSKI, S.F. et al. Starch hydrolysis by the ruminal microflora. Journal of Nutrition, v.122, p.178-190, 1992. Disponível em: <http://jn.nutrition.org/cgi/reprint/122/1/ 178.pdf>. Acesso em: 15 dez. 2009.

LINDEMANN, M.D. et al. Effect of age, weaning and diet on digestive enzyme levels in the piglet. Journal of Animal Science, v.62, p.1298-1307, 1986. Disponível em: <http:// jas.fass.org/cgi/reprint/62/5/1298.pdf >. Acesso em: $15 \mathrm{dez}$. 2009.

NERY, V.L.H. et al. Adição de enzimas exógenas para leitões dos 10 aos $30 \mathrm{~kg}$ de peso. Revista Brasileira de Zootecnia, v.29, p.794-802, 2000. Disponível em: <http://www.scielo.br/ pdf/rbz/v29n3/5825.pdf $>$. Acesso em: 15 dez. 2009. doi: $10.1590 / \mathrm{S} 1516-35982000000300022$.

NRC. Nutrient Requirements of Swine. 10.ed. Washington: National Academy, 1998. 83p.

NETO, J.V. Milho duro e dentado na forma de grãos secos e silagem de grãos úmidos para leitões dos 7 aos 15kg. 2006. 44f. Dissertação (Mestrado em Zootecnia) Curso de Pós-graduação em Zootecnia, Universidade Federal de Lavras, MG.

OLIVEIRA, V. et al. Substituição do milho por casca de café em rações isoenergéticas para suínos em crescimento e terminação. Ciência e Agrotecnologia, v.25, p.424-436, 2001.
Disponível em: <http://www.editora.ufla.br/revista/25_2/ art22.pdf $>$. Acesso: 15 dez. 2009.

PHILIPPEAU, C.; DOREAU, M. Influence of genotype and ensiling of corn grain on in situ degradation of starch in the rumen. Journal of Dairy Science, v.81, p.2178-2184, 1998. Disponível em: 〈http://jds.fass.org/cgi/reprint/81/8/2178.pdf〉. Acesso em: 15 dez. 2009.

ROSTAGNO, H.S. et al. Tabelas brasileiras para aves e suínos: composição de alimentos e exigências nutricionais. 2.ed. Viçosa, MG: Universidade Federal de Viçosa, 2005. 186p.

SILVA, D.J.; QUEIROZ, A. C. Análise de alimentos: métodos químicos e biológicos. 3.ed. Viçosa, MG: Universidade Federal de Viçosa, 2002. 235p.

TESTER, R.F.; QI, X. Molecular basis of the gelatinisation and swelling characteristics of waxy barley starches grown in the same location during the same season. Part I. Composition and alpha-glucan fine structure. Journal of Cereal Science, v.39, p.47-56, 2004

WEURDING, R.E. et al. In vitro starch digestion correlates well with rate and extent of starch digestion in broiler chickens. Journal of Nutrition, v.131, p.2336-2342, 2001. Disponível em: <http://jn.nutrition.org/cgi/reprint/131/9/2336.pdf>. Acesso em: 15 dez. 2009.

WISEMAN, J. et al. Relationship between apparent metabolisable (AME) values and in vivo/in vitro starch digestibility of wheat for broilers. World's Poultry Science Journal, v.56, p.305-318, 2000. 